CAHIER DE RECHERCHE \#1007E

Département de science économique

Faculté des sciences sociales

Université d'Ottawa
WORKING PAPER \#1007E

Department of Economics

Faculty of Social Sciences

University of Ottawa

\title{
Democracy, inequality and the environment when citizens can mitigate privately or act collectively ${ }^{*}$
}

\author{
Sophie Bernard ${ }^{\dagger}$, Louis Hotte ${ }^{\ddagger}$ and Stanley L. Winer ${ }^{\S}$
}

October 2010

\footnotetext{
* This paper has benefited from comments by Gamal Atallah, Hassan Benchekroun, Joan Canton, Ronan Congar, Thorsten Janus, Zhiahao Yu and seminar participants at University of Ottawa 2008, CREE 2008, EAERE Amsterdam 2009, Journées Louis-André Gérard-Varet Marseille 2009, Montreal Natural Resources and Environmental Workshop 2009, WCERE Montreal 2010. Remaining errors are ours. Winer's research was supported by the Canada Research Chair Program. This work was partly supported by a research grant from the SSHRC and from the FQRSC.

† Centre d'économie de la Sorbonne, Paris School of Economics, Université Paris 1 Panthéon-Sorbonne, $106-112$ Boulevard de l'Hôpital. 75647 Paris cedex 13, France; Email: sophie.bernard@univ-paris1.fr.

‡ Department of Economics, University of Ottawa, 55 Laurier E., Ottawa, Ontario, Canada, K1N 6N5; Email: louis.hotte@uottawa.ca.

$\S$ School of Public Policy \& Administration and Department of Economics, Carleton University and CESifo, 1125

Colonel By Drive, Ottawa, Ontario, Canada, K1S 5B6; Email: stan_winer@carleton.ca.
} 


\begin{abstract}
We study the political economy of the environment in autocratic, weak and strong democracies when individuals can either mitigate the health consequences of domestic pollution privately or reduce pollution collectively through public policy. The setting is that of a small open economy in which incomes depend importantly on trade in dirty goods, where income inequality and the degree to which ordinary citizens exert voice in each dimension of the policy process distinguishes elites and ordinary citizens. The recognition that the health consequences of pollution can be dealt with privately at a cost adds an important dimension to the analysis of the political economy of environmental regulation, especially for an open economy. When private mitigation is feasible, inequality of incomes leads to an unequal distribution of the health burden of pollution (in accordance with the epidemiologic evidence), thus polarizing the interests of citizens in democracies and of ordinary citizens and elites in non-democratic regimes. Inequality in the willingness to bear the cost of private mitigation in turn interacts with the pollution costs and income benefits of trade in dirty goods to further polarize interests concerning both environmental stringency and the regulation of trade openness. In this context, we show how the ecofriendliness ranking of different political regimes varies with the cost of private mitigation and with the extent of income inequality, tending to converge when mitigation costs are high, and even producing a ranking reversal between democracies and autocracies, and between weak and strong democracies, when costs lie in an intermediate range.
\end{abstract}

Key words: pollution, environmental regulation, private mitigation, income inequality, democracy, trade, welfare, collective choice, political economy.

JEL Classification: C7, D7, F18, Q56.

\title{
Résumé
}

Nous étudions les choix de politiques environnementales en prenant en compte le fait que les effets de la pollution sur la santé des gens peuvent être atténués de deux grandes manières : soit par des mesures personnelles de protection, soit par des politiques publiques de réduction de pollution. Le cadre d'analyse est celui d'une petite économie ouverte dont les revenus dépendent en grande partie de la production et l'exportation de biens polluants. Cette économie est de plus caractérisée par des inégalités de revenus entre les individus et par la manière dont la voix de chaque citoyen est prise en compte par le processus politique. Trois grands types de régimes politiques sont distingués : l'autocratie, la démocratie faible et la démocratie forte. Le fait que les gens aient le choix de se prémunir personnellement contre les effets de la pollution introduit une dimension importante à l'étude de l'économie politique de l'environnement. En effet, on démontre que dans ce cas et en accord avec les études épidémiologiques, une distribution inégale du revenu conduit à une distribution inégale du fardeau de la pollution. Ceci tend à polariser les intérêts des riches et des pauvres en ce qui concernent les politiques environnementales publiques et sur la volonté d'ouverture au commerce international. Nous montrons comment une comparaison des performances environnementales des différents régimes politiques dépend du coût de la protection individuelle et de l'importance des inégalités de revenus. Par exemple, nous démontrons qu'une autocratie peut se classer devant une démocratie dans certains cas, et inversement dans d'autres.

Mots clés: pollution, réglementation environnementale, protection personnelle, inégalité du revenu, démocratie, commerce international, bien-être, choix collectifs, économie politique

Classification JEL: C7, D7, F18, Q56. 


\section{Introduction}

It is well documented that the adverse welfare consequences of pollution are not borne equally. A recurrent factor explaining this inequality that has emerged in the epidemiologic literature is socio-economic status: poorer individuals tend to suffer more from pollution. ${ }^{1}$ This suggests that although measures to mitigate the health effects of pollution do exist, their cost limits their adoption by everyone. Bottled water, water filtration systems, air purifiers, house location, vacations or medicines are examples of such private measures.

Although the role of private mitigation has been examined to some extent in the economics literature, ${ }^{2}$ its effect has been largely neglected in the political economy literature on environmental policy. In this paper, we study the political economy of environmental regulation in autocratic, weak and strong democracies when individuals may mitigate the health consequences of domestic pollution both privately and collectively through public policy actions. The economic setting is that of a small open economy in which domestic incomes depend importantly on the export of dirty goods.

The recognition that the health consequences of pollution can be dealt with privately at a cost as an alternative to collective action adds an important dimension to the analysis of the political economy of the environment, especially in an open economy. We first describe how the possibility of private mitigation tends to drive a wedge between the interests of low and high-income individuals regarding public policy towards the environment. When private mitigation is feasible, inequality of incomes leads to an unequal distribution of the health burden of pollution in accordance with the epidemiologic evidence, thus polarizing interests. Moreover, inequality in the willingness to bear the cost of private mitigation in turn interacts with the pollution costs and income benefits of international trade to further polarize interests concerning environmental stringency and trade openness.

In this context, we investigate how environmental regulation, the regula-

\footnotetext{
${ }^{1}$ See Ash and Fetter (2004), Pearce et al. (2006), Brooks and Sethi (1997), Neidell (2004), Jayachandran (2008) and Evans and Smith (2005) and the reviews of Brunekreef and Holgate (2002) and O'neill et al. (2003). More anecdotally, news stories about the higher pollution suffering among the poorest within developing countries abound (Bernard (2006), Bradsher and Barboza (2006), French (2005), The Economist (2005)).

${ }^{2}$ See, for instance, Coase (1960), Shibata and Winrich (1983), McKitrick and Collinge (2002), Neidell (2009), Hanna (2007), Rosado (2006).
} 
tion of trade openness and equilibrium levels of pollution vary with the cost of private mitigation and with income inequality in political regimes of different types. Three types of regimes are investigated and compared. The first is an autocratic regime where only a rich elite determines what actions the government undertakes. The second regime, in contrast, is a strong democratic one, where the selection of policies responds to political voice exercised by all citizens. The third, which we refer to as weak democracy, is a regime where the elite controls one policy dimension, while elected governments have power only with respect to the other policy dimension. In one case, the rich elite sets trade openness while the level of environmental regulation is left to a government that responds to demands by poorer citizens. In the other case, these roles are reversed.

Comparative analysis highlights the roles of the cost of private mitigation and of income inequality in shaping the nature of political equilibria. When the cost of private mitigation is very high, autocratic and strong democracies adopt the same policies concerning the environment and trade, despite the fact that the rich elites bear a larger share of the drop in national income. This stands in contrast to Congleton (1992) who pioneered the study of the relationship between regime type and environmental control, and who argues that rich elites in autocratic regimes prefer less regulation. ${ }^{3}$

At intermediate cost levels - that is, when only the rich can afford private mitigation - an increase in the influence of lower income citizens, as occurs in strong democracies, leads to the adoption of stricter environmental controls. However, in this case, we show that the multi-dimensionality of the policy space in elections leads to indeterminacies regarding environmental outcomes when comparing weak and strong democracies. And when the cost of private mitigation is low, so that everyone can protect themselves privately to some extent, we show that a fully democratic regime may adopt laxer environmental policies than an autocratic one because once protected, the poor's willingness to pay for a cleaner environment becomes low.

Concerning income inequality, we identify various conditions under which increased inequality leads to a reordering of political regime types in terms of equilibrium pollution levels. The gist of the argument is based on our proposition that the willingness to pay for pollution reductions varies non-

\footnotetext{
${ }^{3}$ Subsequent contributions include Murdoch et al. (1997), Fredriksson et al. (2005), Farzin and Bond (2006), Dasgupta et al. (2006) and Fredriksson and Wollscheid (2007). All point to a somewhat more complex relationship between political institutions and environmental policy.
} 
monotonically with income. When rich and poor choose to mitigate equally, as is more likely to occur under low income inequality, the rich prefer relatively more pollution reductions: An autocracy thus leads to lower pollution levels than a democracy. But when private mitigation is a luxury that only the rich can afford, as is more likely to happen under high income inequality, then the rich prefer higher pollution levels than the poor: An autocracy thus leads to higher pollution levels than a democracy.

It can therefore be seen that higher income is not always associated with demands for a cleaner environment, the usual normal good prediction. This may appear to go against the common grain, and in particular to be at odds with the Environmental Kuznets Curve (EKC) hypothesis concerning the relationship between average income and pollution. But in our framework, income inequality among citizens matters in addition to average national income. Moreover, it is important to keep in mind that demand for a cleaner environment is not the same as demand for better health, and there tends to be a disconnect between the two when private mitigation technologies are available. Our analysis concurs with micro-based evidence provided by Kahn and Matsusaka (1997) and Kristrom and Riera (1996) to the effect that within a community or country, demand for environmental regulation can be lower among higher-income individuals. ${ }^{4}$

Previous work on individual demands for control of the environment typically uses explanations that depend on differences in either the source of factor income, income levels which affect the willingness-to-pay, or an exogenous preference for the environment. The analysis of Eriksson and Persson (2003) appears to be the only one yet to incorporate the fact that higher income individuals may be less affected by pollution, though it does so in an exogenous fashion. By making the choice of private mitigation effort endogenous, we can offer additional insight.

The analysis in the paper is carried out in the context of a small open economy, where a tariff affects the extent of specialization in production of a dirty good and hence the amount of pollution. There are several reasons for this modeling choice, one that leads to a framework where there is an important interaction of mitigation costs and the costs and benefits of trade that results in the polarization of citizen interests, as we noted above. Many

\footnotetext{
${ }^{4}$ See also recent empirical observations that the effect of average income on environmental regulation may actually turn negative once one controls for the level of democracy, including Torras and Boyce (1998), Fredriksson et al. (2005), Farzin and Bond (2006) and Dasgupta et al. (2006).
} 
countries are small and open, and in that context we agree with others that the determination of environmental regulation is bound up with the choice of trade openness (See, for example, Hillman and Ursprung (1992), Schulze and Ursprung (2001) and Copeland and Taylor (2003)). ${ }^{5}$

It should also be noted that in the open economy, where regulation of trade openness is also an issue in addition to direct regulation of pollution, the policy space in weak and strong democracies is multi-dimensional. The resulting analysis leads to interesting ambiguities when it comes to comparing the eco-friendliness of different regimes. Multi-dimensionality introduces different criteria with which to test which regime is the most eco-friendly - on direct regulation, or by control of specialization in the production of dirty goods. The interesting study by Damania et al. (2003), for instance, compares the ecological performance of various regimes by the stringency of their environmental regulation. But what if, as in the models explored here, a weak democracy combines stricter regulation with more openness to trade in dirty goods?

The paper extends the analysis of Hotte and Winer (2008) to more general characterizations of production technologies and consumer preferences, to a wider range of, and more detailed specification of political regimes, introduces trade openness as an explicit and continuous policy instrument, and studies the effects of changes in income inequality. It thus provides a richer set of results. Other noteworthy theoretical enquiries concerning the relationship of environmental policies and trade openness include Pethig (1976), Chichilnisky (1994), Copeland and Taylor (1994) and McAusland (2003). It should be noted that none of these studies considers the role of private mitigation.

The paper is organized as follows. In section 2, we lay down the basic features of a small open economy with pollution emissions, environmental regulation and a trade tariff governing the extent of trade openness. Individual welfare functions are introduced in section 3 , where we characterize the optimal choice of effort to attenuate the adverse health effects of pollu-

\footnotetext{
${ }^{5}$ Relatedly, Markusen (2010) argues that in choosing to concentrate on technology and factor endowment differences, trade economists have ignored for too long the link between preferences and income levels in explaining trade patterns. For instance, Mitra and Trindade (2005) show that given identical non-homothetic preferences, income distribution within a country affects the trade pattern. In our case, though preferences for traded goods are homothetic (for fixed regulation), trade patterns are still affected by income distribution because of its effect on the demands for environmental policies.
} 
tion as a function of given individual incomes. In section 4, we derive the general equilibrium effects of given pollution regulations and trade openness on national income and pollution levels. These effects are then introduced into the individual welfare functions, thus allowing for the determination of private mitigation efforts in an economic equilibrium. The individually preferred combinations of public policy and private mitigation efforts in an economic equilibrium are then derived as functions of individual national income shares and the cost of mitigation. In section 5, we introduce regimes differentiated by a role for voice for citizens in each policy dimension, and derive policy equilibria for autocratic, weak and strong democracies, and we study the effects of varying private mitigation costs and income inequality. Section 6 concludes this investigation of the role of private mitigation in the political economy of the environment in open economies.

\section{The economy}

We suppose at the outset that goods fall into one of two categories: clean or dirty. The difference between them occurs at the production stage only. The clean good (good 1) does not generate any pollution when produced, but a dirty one (good 2) does.

\subsection{The aggregate demand}

Clean and dirty goods are undistinguishable when it comes to their consumption. Consumers just prefer more to less, and assign more value to a balanced basket. Hence, if we let $z \in \Re^{+}$denote the real national income level, then this level is achieved by combining the two types of goods in quantities $x_{1}$ and $x_{2}$ as per function $F(\mathbf{x}) \geq z, \mathbf{x} \equiv\left(x_{1}, x_{2}\right)$, which is strictly increasing, strictly quasi-concave and continuous. If $\mathbf{p} \equiv\left(p_{1}, p_{2}\right)$ is the domestic price vector of 1 and 2 , then the total cost of $z$ can be represented by the following cost minimization function:

$$
e(\mathbf{p}, z) \equiv \min _{\mathbf{x}}\{\mathbf{p x} \mid z \leq F(\mathbf{x})\} .
$$

$e(\mathbf{p}, z)$ has the usual properties of a cost function. By Shephard's lemma, the conditional demand for good $i$ is given by $x^{i}(\mathbf{p}, z)=e_{i}(\mathbf{p}, z)$, where subscript $i$ denotes the partial derivative with respect to the price of good $i{ }^{6}$

\footnotetext{
${ }^{6}$ When there is no possibility of confusion, the subscript of a function denotes a partial derivatives.
} 
$e(\mathbf{p}, z)$ also represents the national nominal expenditure function at income level $z$.

\subsection{Aggregate supply and pollution}

Goods 1 and 2 can be produced either domestically or imported. Let $\mathbf{y} \equiv$ $\left(y_{1}, y_{2}\right)$ denote their domestic production vector. Good 2 generates $q(\theta)$ units of pollution per unit produced, where $\theta$ refers to the cleanliness of the production technology being used. The ambient pollution level is thus given by

$$
Q=q(\theta) y_{2}, \text { with } q(\theta)>0 \text { and } q^{\prime}(\theta)<0 .
$$

Cleaner production is however costly in terms of reduced product in sector 2 as represented by the following output function:

$$
y_{2}=(1-\theta) f^{2}\left(\mathbf{v}_{2}\right),
$$

where $\mathbf{v}_{2}$ denotes an input vector and $f^{2}$ is the output function for good 2 in the absence of efforts to control emissions.

The technology and production resources available in the economy are summarized by the strictly convex production possibility set $G(\mathbf{y}, \theta) \leq 0$. The gross domestic product (GDP) function at domestic prices is thus defined as

$$
g(\mathbf{p}, \theta) \equiv \max _{\mathbf{y}}\{\mathbf{p y} \mid G(\mathbf{y}, \theta) \leq 0\} .
$$

$g(\mathbf{p}, \theta)$ has the usual properties of a profit function. By Hotelling's lemma, we have $y^{i}(\mathbf{p}, \theta)=g_{i}(\mathbf{p}, \theta)$.

\subsection{The general economic equilibrium}

For a small open economy, we have $\mathbf{p}=\left(p_{1}^{*}+\tau, p_{2}^{*}\right)$, where $p_{i}^{*}$ is the world price of good $i$ and $\tau$ is the tariff per unit of good 1 imported. The imports of good 1 are given by $x^{1}(\mathbf{p}, z)-y^{1}(\mathbf{p}, \theta)$.

The economy's total earnings - or, equivalently, national nominal income $I$ - are equal to GDP plus tariff revenues; that is, $I=G D P+\tau\left(x_{1}-y_{1}\right)$. With balanced trade and government budget, the economy's general equilibrium is fully determined by the following expression:

$$
e(\mathbf{p}, z)=g(\mathbf{p}, \theta)+\tau\left(x^{1}(\mathbf{p}, z)-y^{1}(\mathbf{p}, \theta)\right) .
$$

For fixed $\theta$ and $\tau, z$ is the sole endogenous variable in expression (5); we can thus write $z=z(\theta, \tau)$ and $Q=Q(\theta, \tau)$. 


\section{Individual welfare and private mitigation efforts}

Individual welfare functions are now introduced, and the optimal choice of effort to attenuate the adverse health effects of pollution is determined as a function of given individual incomes. A priori, individuals differ solely by the share of the national income that they receive, denoted $s{ }^{7}$ We shall refer to each individual type by his or her income share $s$.

Following Mayer (1984), we simplify by assuming that tariff revenues are redistributed neutrally with respect to pre-fisc income parameter $s$. Since $z$ is the only real wealth being created, this implies that individual $s$ gets to spend $s z$.

The well-being of individual $s$ depends positively on two variables: a (pure) consumption level $c_{s}$ and a health condition $h_{s}$. The health condition depends negatively on the ambient pollution level $Q$, but this effect can be individually attenuated with pollution-mitigation effort $d_{s} .{ }^{8}$ The following function summarizes individual welfare levels:

$$
U_{s}=u\left(c_{s}\right)+h\left(d_{s}, Q\right) .
$$

Function $u$ is strictly increasing, strictly concave and continuous. Function $h$ has the following binary properties:

$$
h(d, Q)= \begin{cases}h_{0}-\bar{\ell}(Q) & \text { if } d<\underline{d} \\ h_{0}-\underline{\ell}(Q) & \text { otherwise. }\end{cases}
$$

Parameter $h_{0}$ represents the health condition in the absence of pollution (that is, the best possible health). Functions $\underline{\ell}$ and $\bar{\ell}$ correspond to the health deterioration due to pollution, respectively with and without private mitigation, with $\bar{\ell}(Q)>\underline{\ell}(Q), \bar{\ell}^{\prime}(Q)>0, \underline{\ell}^{\prime}(Q)>0$ and $\bar{\ell}^{\prime \prime}(Q)>0, \underline{\ell}^{\prime \prime}(Q)>0$.

Since $d$ is costly, the choice of private mitigation is really binary: one either chooses effort level $\underline{d}$ or none at all. The health gain from mitigation effort $\underline{d}$ is expressed as follows:

$$
\Delta(Q) \equiv \bar{\ell}(Q)-\underline{\ell}(Q)>0 .
$$

\footnotetext{
${ }^{7}$ Parameter $s$ subsumes the various determinants of income such as innate skills, education, or even ability to appropriate existing resources.

${ }^{8}$ In the literature, private pollution-mitigation efforts are also referred to as defensive expenditures and averting efforts. For more detailed analyzes of its implications for consumer behavior, see Courant and Porter (1981), Shibata and Winrich (1983), Bartik (1988) and McKitrick and Collinge (2002).
} 
It is assumed that this health gain increases with the pollution level; that is, $\Delta^{\prime}(Q)>0$. This equivalently implies that the health benefit from a reduction in pollution is lower for those who invest in private mitigation; that is, $\bar{\ell}^{\prime}(Q)>\underline{\ell}^{\prime}(Q)$.

Note that according to expression (7), the private mitigation technology is summarized by parameter $\underline{d}$ - a measure of the cost of private mitigation - and function $\Delta(Q)$ - a measure of its effectiveness. Ultimately, both measures will depend on the type, or mix, of pollutant under consideration.

Real income can be used for either pure consumption or pollution mitigation. The following budget constraint must therefore be respected: $c_{s}+d_{s}=$ $s z$. The individual welfare maximizing problem is expressed as:

$$
\begin{aligned}
& \max _{c_{s}, d_{s}} U_{s}=u\left(c_{s}\right)+h\left(d_{s}, Q\right), \\
& \text { s.t. } c_{s}+d_{s}=s z .
\end{aligned}
$$

For given $z$ and $Q$, individual $s$ therefore chooses $d_{s}^{*}=\underline{d}$ if, and only if, $u(s z-\underline{d})-\underline{\ell}(Q) \geq u(s z)-\bar{\ell}(Q)$ or, equivalently,

$$
\Delta(Q) \geq u(s z)-u(s z-\underline{d}) .
$$

This inequality says that an individual will spend on private mitigation as long as the drop in consumption utility does not exceed the gain in health condition. Defining $\tilde{s}$ as the individual who is indifferent between spending on private mitigation or not, we have

$$
\Delta(Q)=u(\tilde{s} z)-u(\tilde{s} z-\underline{d}) .
$$

With $u_{c c}<0$, the right-hand side of (11) is decreasing in $s$. Consequently, we have that $d_{s}^{*}=0$ if $s<\tilde{s}$ and $d_{s}^{*}=\underline{d}$ otherwise and, hence, the following proposition:

Proposition 1 Private-mitigation effort is (weakly) increasing in individual income shares.

With decreasing marginal utility of consumption, the welfare loss from spending a fixed amount $\underline{d}$ decreases with income. Given that the health gain is the same regardless of income, we have the above proposition. Now in the absence of private mitigation, a decreasing marginal utility of consumption 
makes environmental quality a normal good, as is typically assumed in the literature on trade and the environment. This is true, in fact, for any fixed private-mitigation effort:

Proposition 2 For given $d_{s}$, the marginal willingness to pay (MWTP) for environmental improvements increases with income share $s$.

Proof: Generally, the utility of an individual $s$ who spends amount $d_{s}$ on private mitigation and suffers $\ell(Q)$ from pollution is given by $U_{s}=$ $u\left(s z-d_{s}\right)+h_{0}-\ell(Q)$. Taking the total differential and equating it to zero yields $d(s z) / d Q=\ell^{\prime}(Q) / u_{c}\left(s z-d_{s}\right)$, which corresponds to the MWTP. Since $u_{c c}<0$, the MWTP increases with $s$ for fixed $d_{s}$.

However, introduction of private mitigation blurs the monotonic relationship between income and the demand for environmental quality:

Proposition 3 For a range of income shares directly above $\tilde{s}$, the marginal willingness to pay (MWTP) for environmental improvements is lower than from a range of income shares directly below $\tilde{s}$.

Proof: From (6) and (7), we have, for all $s, \bar{\ell}^{\prime}(Q) / u_{c}(s z)>\underline{\ell}^{\prime}(Q) / u_{c}(s z-\underline{d})$. By the definition of $\tilde{s}$, since the inequality is strict and the MWTP is continuous for given $d_{s}$, there must exist $\varepsilon>0$ such that for any $\delta \in(0, \varepsilon)$ we have $\bar{\ell}^{\prime}(Q) / u_{c}((\tilde{s}-\delta) z)>\underline{\ell}^{\prime}(Q) / u_{c}((\tilde{s}+\delta) z-\underline{d})$.

Equation (12) also determines an implicit relationship between $\tilde{s}$ and variables $z, \underline{d}$ and $Q$, which are taken as given at the individual level. It is easy to verify that $\tilde{s}$ is a decreasing function of $z$ : As the national income increases, more people engage in private mitigation, ceteris paribus. The converse holds if $\underline{d}$ increases: A higher cost of private mitigation reduces recourse to private mitigation. As for the effect of the pollution level, we obtain that $\tilde{s}$ decreases with $Q$ : With higher pollution, more people invest in private mitigation.

\section{Public policy and individual welfare in an economic equilibrium}

The production of good 2 generates pollution, and so trade exacerbates the pollution problem whenever the country's comparative advantage lies with 
the production of good 2. In this situation, we shall assume that the government can intervene with two policy instruments: It can directly regulate the cleanliness of the production technology, as summarized by parameter $\theta$ above. Alternatively, it can set the degree of trade openness in order to attenuate the trade-induced specialisation into dirty good $2 .{ }^{9}$ Assuming that the country's comparative advantage lies with the dirty good, the import tariff defined previously in section 2 acts in this situation as a useful proxy for trade openness.

To study the links between individual welfare and public policy actions in the presence of private mitigation, we begin by looking at how given public policies affect the general equilibrium of the economy, and then turn to individual welfare in this economic equilibrium. Analysis of political equilibria comes later.

\subsection{The general equilibrium effects of (given) environmental and trade po- lices}

Recall that equation (5) defines the implicit relation between $z$ and the policy instruments. Total differentiations with respect to changes in $\theta$ and $\tau$ respectively yield:

$$
\begin{aligned}
& e_{z}(\mathbf{p}, z) d z=g_{\theta}(\mathbf{p}, \theta) d \theta+\tau\left(x_{z}^{1}(\mathbf{p}, z) d z-y_{\theta}^{1}(\mathbf{p}, \theta) d \theta\right) \\
& e_{z}(\mathbf{p}, z) d z=\tau\left\{\left(x_{1}^{1}(\mathbf{p}, z)-y_{1}^{1}(\mathbf{p}, \theta)\right) d \tau+x_{z}^{1}(\mathbf{p}, z) d z\right\} .
\end{aligned}
$$

Expression (13) indicates that an increase in $\theta$ reduces national income through a decrease in GDP (negative technological effect $g_{\theta}$ ) and a decrease in tariff revenue as more of good 1 gets locally produced (positive price effect $\tau y_{\theta}^{1}$ ). In the absence of an adjustment in output $z$, expenditures exceed income. A decrease in output re-establishes the equilibrium through a reduction in expenditures $\left(e_{z} d z\right)$ which induces a further reduction in tariff revenues from a drop in demand for good $1\left(x_{z}^{1} d z\right)$.

\footnotetext{
${ }^{9} \mathrm{We}$ choose those two instruments because they are extensively used in practice and have been extensively analysed. According to Hueth and Melkonyan (2009), "The regulation of environmental risk is dominated by the use of standards. Although performance incentives (e.g., Pigouvian taxes and emissions-trading programs) are sometimes employed, standards remain the core component of environmental and safety regulatory design across issues ranging from worker safety and hazardous materials control to water and air pollution mitigation." (Cited in Heyes and Kapur, 2010) Note also that according to the Lerner symmetry proposition, an import tariff on the clean good has the same effect as an export tax on the dirty good (Corden, 1984).
} 
In the case of an increase in tariff, note first that expression (14) makes use of the fact that $d p_{1}=d \tau$ for a small open economy. Tariff revenues decrease because of a fall in imports. This is matched by a decrease in expenditures $\left(e_{z} d z\right)$ which induces a further reduction in tariff revenues as the demand for good 1 drops by $x_{z}^{1} d z$.

Now the real output level $z$ can be conveniently expressed by the following problem:

$$
z(\mathbf{p}, I) \equiv \max _{\mathbf{x}}\left\{F(\mathbf{x}) \mid p_{1} x_{1}+p_{2} x_{2} \leq I\right\} .
$$

$z(\mathbf{p}, I)$ represents the national real output function; it has the usual properties of an indirect utility function. By Roy's identity, the (ordinary) demand for good $i$ is given by $\tilde{x}^{i}(p, I)=-z_{i}(\mathbf{p}, I) / z_{I}(\mathbf{p}, I)$. The conditional demand for good 1 can thus be expressed as $x^{1}(\mathbf{p}, z)=\tilde{x}^{1}(\mathbf{p}, e(\mathbf{p}, z))$, so that $x_{z}^{1}(\mathbf{p}, z)=$ $\tilde{x}_{I}^{1}(\mathbf{p}, e(\mathbf{p}, z)) e_{z}(\mathbf{p}, z)$. Inserting this into total differential equations (13) and (14), we get

$$
\begin{aligned}
\frac{d}{d \theta} z(\theta, \tau) & =\frac{g_{\theta}-\tau y_{\theta}^{1}}{\left(1-\tau \tilde{x}_{I}^{1}\right) e_{z}}<0, \\
\frac{d}{d \tau} z(\theta, \tau) & =\frac{\tau\left(x_{1}^{1}-y_{1}^{1}\right)}{\left(1-\tau \tilde{x}_{I}^{1}\right) e_{z}}<0 .
\end{aligned}
$$

Note that expression $1 /\left(1-\tau \tilde{x}_{I}^{1}\right)$ is the tariff multiplier (Jones, 1969) and is generally assumed to be positive (Anderson and Neary, 2005:33). As for the general pollution effects of regulation and tariff, they are respectively given by

$$
\begin{aligned}
\frac{\partial}{\partial \theta} Q(\theta, \tau) & =q^{\prime}(\theta) y_{2}-q(\theta) y_{\theta}^{2}<0 \\
\frac{\partial}{\partial \tau} Q(\theta, \tau) & =q(\theta) y_{1}^{2}<0
\end{aligned}
$$

Expressions (16) and (17) correspond to the real national income cost of each policy, while (18) and (19) are the benefits in terms of lower pollution.

\subsection{Public policy and individual welfare in an economic equilibrium}

Let $\Omega$ generically represent a single policy instrument. Then the individual welfare effect of a marginal change in a policy instrument - either environ- 
mental regulation or trade openness - is given by

$$
\frac{\partial U_{s}^{*}}{\partial \Omega}=\left[u_{c}\left(c_{s}^{*}\right) s\right] z_{\Omega}-\left[\ell^{\prime}(Q)\right] Q_{\Omega}, \text { where } \Omega \in\{\theta, \tau\} .
$$

$z_{\Omega}$ and $Q_{\Omega}$ are the economy-wide effects identified in equations (16) to (19). The terms between square brackets correspond to the respective weights that each individual assigns to these costs and benefits.

Expression (20) has a convenient economic interpretation in terms of marginal willingness to pay for environmental improvements expressed in units of real national income $z$, denoted $\omega_{s}$. It is given by

$$
\omega_{s} \equiv \frac{\ell^{\prime}(Q)}{u_{c}\left(c_{s}^{*}\right) s} .
$$

On the other hand, the national income cost of that unit reduction in pollution, using instrument $\Omega$, is given by $z_{\Omega} / Q_{\Omega}$. Consequently, individual $s$ gains from a marginal increase in $\Omega$ if

$$
\omega_{s}>\frac{z_{\Omega}}{Q_{\Omega}},
$$

which does hold if the derivative in (20) is positive.

Since $z_{\Omega} / Q_{\Omega}$ is independent of an individual's type, differences in interest stem from differences in the marginal willingness to pay $\omega_{s}$. Through straightforward algebra, it can be verified that for $d=0, \omega_{s}$ decreases with $s$ if, and only if, $\sigma \equiv-u_{c c} c / u_{c}<1$. This is because an individual with higher $s$ faces the following tradeoff: on the one hand, he or she incurs a higher cost of regulation in absolute value; on the other hand, their marginal utility of income is lower. ${ }^{10}$ If $\sigma<1$, the cost effect prevails and the marginal willingness to pay decreases with income share. The opposite holds if $\sigma>1$.

Since this trade-off has been noted and studied elsewhere in the literature, while our purpose is to point to and study the role of private mitigation when incomes are not equal, we shall remove the ambiguity by assuming that $\sigma=1 .^{11}$ The cost effect is then exactly offset by the marginal utility effect, so that in the absence of any private mitigation effort, $\omega_{s}$ is independent of income share. Any remaining divergence of the interests of citizens of varying incomes is then driven only by the possibility of private mitigation.

\footnotetext{
${ }^{10}$ In a more general context, higher income individuals may also end-up supporting a higher cost of regulation because they tend to own more capital goods while capitalintensive goods pollute more, as in Copeland and Taylor (2003, chapter 4) and McAusland (2003).

${ }^{11}$ McAuland (2003) provides a detailed analysis of the role of $\sigma$.
} 


\subsection{Environmental regulation and private mitigation}

In order to better understand the role played in the economic equilibrium by the introduction of private mitigation, we now consider the case of two types of individuals with low and high income shares denoted $\underline{s}$ and $\bar{s}$ respectively. $U_{\bar{s}}^{0}$ and $U_{\underline{s}}^{0}$ represent their respective welfare levels in the absence of private mitigation spending, and given that $\sigma=1$, both types then prefer the same regulation level, denoted $\theta^{0}$.

$U_{\bar{s}}^{d}$ and $U_{s}^{d}$ denote the respective welfare levels when both types spend $\underline{d}$ on private mitigation. We first note that with private mitigation, the preferred level of public environmental control is lower than in its absence for both types. We have then:

Proposition 4 The preferred environmental regulation level decreases with private mitigation efforts.

Proof: In the absence of private mitigation, the preferred mitigation level $\theta^{0}$ is defined by

$$
\frac{\overline{\ell^{\prime}}\left(Q\left(\theta^{0}, \tau\right)\right)}{u_{c}\left(s z\left(\theta^{0}, \tau\right)\right) s}=\frac{z_{\theta}\left(\theta^{0}, \tau\right)}{Q_{\theta}\left(\theta^{0}, \tau\right)}
$$

With $\sigma=1$, this equality is respected for all $s$. With private mitigation, the willingness to pay for regulation drops since $\underline{\ell}^{\prime}(Q)<\bar{\ell}^{\prime}(Q)$ by assumption and $u_{c}(s z-\underline{d})>u_{c}(s z)$ since $u_{c c}<0$. As a result, with private mitigation, the left-hand side of (23) becomes strictly smaller than the right-hand side for all $s$ at $\theta_{0}$, which implies that a decrease in regulation raises welfare.

It is important to point out also that for two individuals who invest in private mitigation, the preferred regulation level is not equal in the presence of mitigation efforts. In this respect, we can state the following two propositions:

Proposition 5 For those who invest in private mitigation, the preferred regulation level increases with income share.

Proof: Without loss of generality, take two individuals with income shares $\bar{s}$ and $\underline{s}$, with $\bar{s}>\underline{s}$. It suffices to show that with private mitigation, the willingness to pay for regulation is higher for $\bar{s}$ than for $\underline{s}$. To this end, we must simply show that $u_{c}(\bar{s} z-\underline{d}) \bar{s}<u_{c}(\underline{s} z-\underline{d}) \underline{s}$. 
Let $s_{1} z=\bar{s} z-\underline{d}$ and $s_{2} z=\underline{s} z-\underline{d}$. Since $\sigma=1$, we have $u_{c}\left(s_{1} z\right) s_{1}=$ $u_{c}\left(s_{2} z\right) s_{2}$ or, by substitution, $u_{c}\left(s_{1} z\right)(\bar{s}-\underline{d} / z)=u_{c}\left(s_{2} z\right)(\underline{s}-\underline{d} / z)$. Rearranging, we get $u_{c}\left(s_{1} z\right) \bar{s}-u_{c}\left(s_{2} z\right) \underline{s}=\left(u_{c}\left(s_{1} z\right)-u_{c}\left(s_{2} z\right)\right) \underline{d} / z<0$. The latter inequality is due to the fact that $u_{c c}<0$ and $s_{1}>s_{2}$. Substituting $s_{1} z=\bar{s} z-\underline{d}$ and $s_{2} z=\underline{s} z-\underline{d}$, we get $u_{c}(\bar{s} z-\underline{d}) \bar{s}<u_{c}(\underline{s} z-\underline{d}) \underline{s}$.

Proposition 6 A single crossing condition For a given trade tariff (or degree of trade openness) $\tau$, the regulation level at which individual $s$ is indifferent between investing in private mitigation or not, denoted $\hat{\theta}_{s}$, if it exists, is unique.

Proof: By substitution, it is straightforward to verify that the following holds:

$$
\frac{\partial U_{s}^{d}}{\partial \theta}<\frac{\partial U_{s}^{0}}{\partial \theta}
$$

Consequently, continuous utility functions $U_{s}^{d}$ and $U_{s}^{0}$ can cross only once as $\theta$ varies.

The essence of propositions 4,5 and 6 is illustrated in figure 1 . We present a case where $\hat{\theta}_{\underline{s}}<\theta_{\underline{s}}^{d}$ and $\hat{\theta}_{\bar{s}} \in\left(\theta_{\bar{s}}^{d}, \theta^{0}\right)$. Hence, the low-income type prefers not to engage in private mitigation even at the regulation level $\theta_{s}^{d}$, while the high-income type chooses not to mitigate at $\theta^{0}$ but does so at $\theta_{\bar{s}}^{\bar{d}}$.

Thus the possibility of private mitigation drives a wedge between the interests of the rich and the poor. Both types would prefer regulation level $\theta^{0}$ if private mitigation were not an option. But with the possibility of mitigation, the figure illustrates a case where the high-income type overall prefers lower regulation level $\theta_{\bar{s}}^{d}$, at which point the welfare of the low-income type drops compared to his welfare at $\theta^{0}$, a reduction in his welfare that happens whether or not the low-income person decides to privately mitigate.

\subsection{Environmental regulation and trade openness}

In order to efficiently reduce the pollution level, the use of both environmental regulation and of the import tariff must respect the following equality: $z_{\theta} / Q_{\theta}=z_{\tau} / Q_{\tau}$. This equality defines an implicit positive relationship between $\theta$ and $\tau$ and is illustrated by the curve labeled $\tau^{e}(\theta)$ in figure 2. Note 


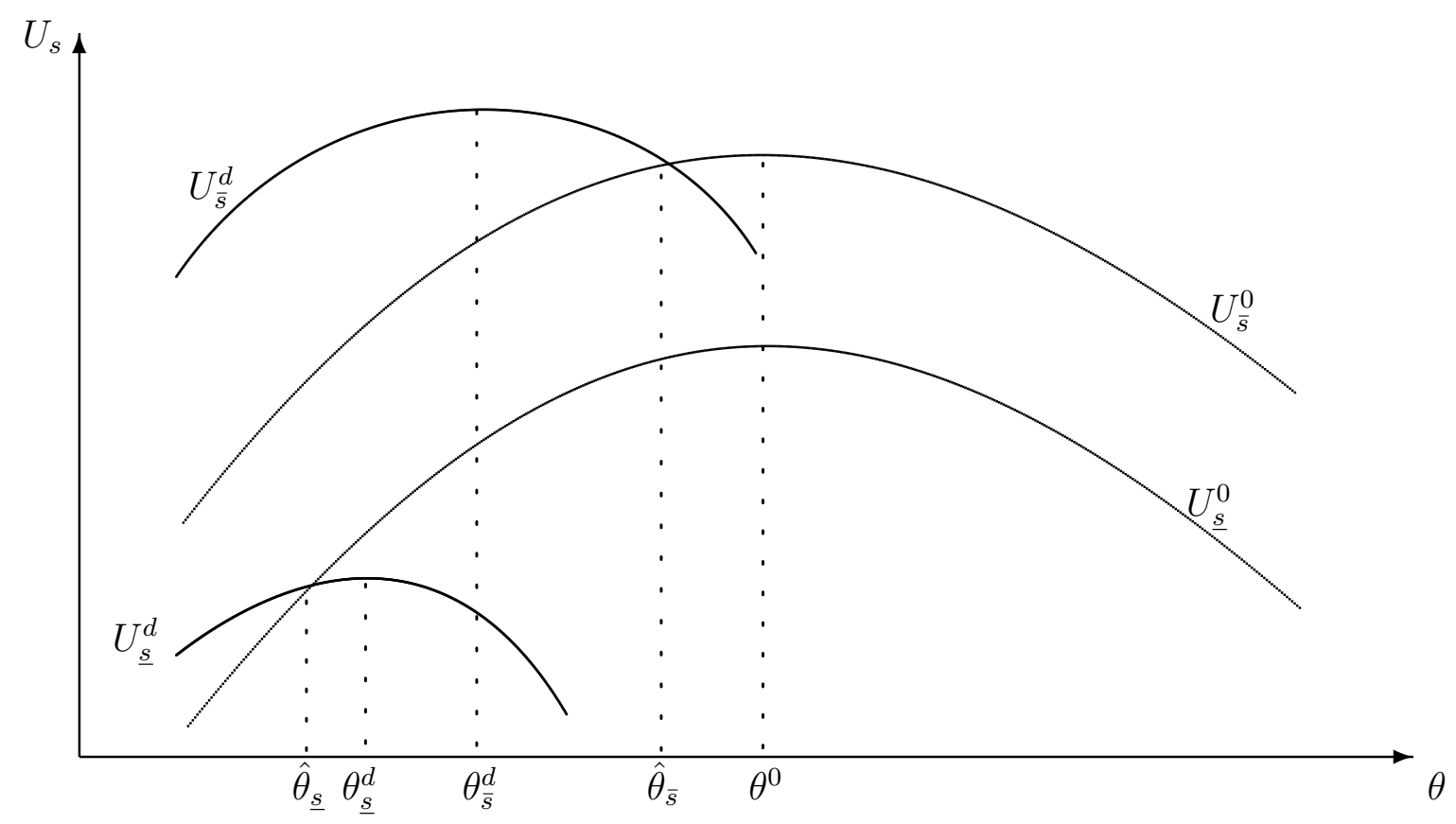

Figure 1: Income shares and individual interests over environmental regulation

that, given the possibility of private mitigation, this curve does not inform us about what the efficient pollution level will (or should) be.

In figure 2, functions $\theta^{0}(\tau)$ and $\theta_{s}^{d}(\tau)$ denote the loci of preferred regulation levels for individual $s$ with respect to the tariff rate $\tau$, respectively without and with private mitigation. (Keep in mind that in the absence of private mitigation, the preferred regulation level is independent of individual type. It is thus not necessary to include subscript $s$.) They are obtained by respecting the following equalities (see expression (20)):

$$
\begin{aligned}
& u_{c}\left(s z\left(\theta_{s}^{0}, \tau\right)\right) s z_{\theta}\left(\theta_{s}^{0}, \tau\right)-\bar{\ell}^{\prime}\left(Q\left(\theta_{s}^{0}, \tau\right)\right) Q_{\theta}\left(\theta_{s}^{0}, \tau\right)=0, \text { for } d_{s}=0 \\
& u_{c}\left(s z\left(\theta_{s}^{d}, \tau\right)-\underline{d}\right) s z_{\theta}\left(\theta_{s}^{d}, \tau\right)-\underline{\ell}^{\prime}\left(Q\left(\theta_{s}^{d}, \tau\right)\right) Q_{\theta}\left(\theta_{s}^{d}, \tau\right)=0, \text { for } d_{s}=\underline{d} .
\end{aligned}
$$

Through implicit differentiation, one can verify that $\theta^{0}(\tau)$ and $\theta_{s}^{d}(\tau)$ are downward slopping. ${ }^{12}$ According to proposition 4, we have $\theta_{s}^{d}(\tau)<\theta^{0}(\tau)$.

\footnotetext{
${ }^{12}$ We assume that the second-order condition is verified and that functions $u$ and $\ell$ are
} 


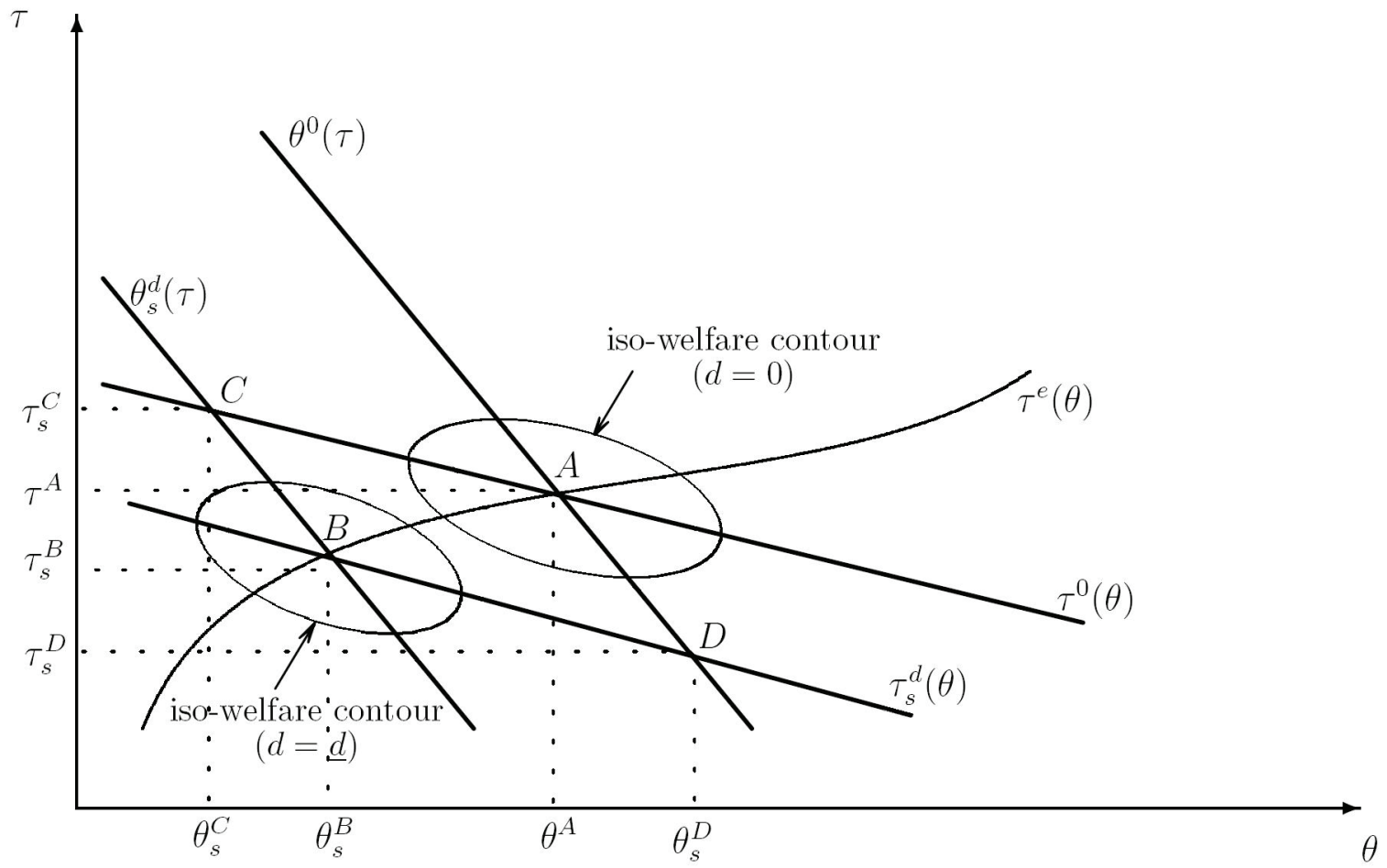

Figure 2: Welfare as a function of public policy and private mitigation efforts 
The loci of the preferred tariff rates are also illustrated as $\tau^{0}(\theta)$ and $\tau_{s}^{d}(\theta)$ and are similarly obtained.

In the absence of private mitigation, welfare reaches a (local) maximum at the intersection of curves $\theta^{0}(\tau)$ and $\tau^{0}(\theta)$, provided that $U_{s}^{0}(\theta, \tau)$ is (locally) strictly concave, which we assume to be the case. ${ }^{13}$ This implies that as $\theta$ increases, curve $\theta^{0}(\tau)$ crosses curve $\tau^{0}(\theta)$ from above and the iso-welfare contour have an ellipse-like shape as illustrated. Given that $d_{s}=0$, welfare decreases as the regulation and tariff combination moves away from $\left(\theta^{A}, \tau^{A}\right)$ in any direction. In the presence of private mitigation, we obtain analogous properties around point $B .{ }^{14}$ Finally, coordinate points $A$ and $B$ must fall on the efficiency curve $\tau^{e}(\theta)$. Indeed, they are characterized by the marginal willingness to pay being simultaneously equal to $z_{\theta} / Q_{\theta}$ and $z_{\tau} / Q_{\tau}$. We therefore have the following propositions:

Proposition 7 The preferred policy combination $\left(\theta^{B}, \tau^{B}\right)$ is decreasing in the cost of private mitigation ( $\underline{d})$ and increasing in the income share (s).

Proof: The first part derives from the fact that after spending on private mitigation, a lower $\underline{d}$ allows for higher consumption, which results in a higher willingness to pay for reducing pollution. The second part is a restatement of proposition 5, generalized to the case of both pollution regulation and a trade tariff. The proof is a straightforward extension to this case.

\subsection{Considering environmental regulation, trade openness and private mit- igation together}

We are now in a position to derive an individual's overall preferred combination in economic equilibrium of all three variables that can be used to improve one's health condition: collective action using environmental regulation and trade openness (the tariff), and private mitigation effort.

We shall restrict our analysis to the surface formed by $(\theta, \tau) \in\left(\left(\theta_{s}^{C}, \tau_{s}^{D}\right),\left(\theta_{s}^{D}, \tau_{s}^{C}\right)\right)$, where it is assumed that $U^{0}(\theta, \tau)$ and $U^{d}(\theta, \tau)$ are both strictly concave. Coordinate points $A$ and $B$ therefore define two local maxima and policy combination $\left(\theta_{s}^{B}, \tau_{s}^{B}\right)$ is preferred to $\left(\theta^{A}, \tau^{A}\right)$ if, and only if, the following

\footnotetext{
sufficiently concave and convex, respectively.

${ }^{13}$ That is, the Hessian matrix of $U_{s}^{0}(\theta, \tau)$ is negative definite at $\left(\theta^{A}, \tau^{A}\right)$.

${ }^{14}$ To better visualize, note that figure 1 is a transversal cut of figure 2 with $\tau$ held constant.
} 
holds:

$$
u\left(s z\left(\theta^{A}, \tau^{A}\right)\right)-\bar{\ell}\left(Q\left(\theta^{A}, \tau^{A}\right)\right)<u\left(s z\left(\theta_{s}^{B}, \tau_{s}^{B}\right)-\underline{d}\right)-\underline{\ell}\left(Q\left(\theta_{s}^{B}, \tau_{s}^{B}\right)\right) .
$$

Whether condition (26) holds depends in part on the magnitude of the private mitigation cost $\underline{d}$. We have the following proposition:

Proposition 8 Let $\underline{d}(s)$ denote the maximum value for which policy $\left(\theta_{s}^{B}, \tau_{s}^{B}\right)$ is preferred by an individual to $\left(\theta^{A}, \tau^{A}\right)$. $\underline{d}(s)$ exists and is increasing in $s$.

Proof: Using the envelope condition, we have $\partial U_{s}^{d} / \partial \underline{d}=-u^{\prime}\left(s z\left(\theta_{s}^{B}, \tau_{s}^{B}\right)-\right.$ $\underline{d})<0$. Existence derives from the continuity properties. The fact that $\underline{d}(s)$ is increasing can be shown by first assuming that (26) holds with equality for some $s$. It is then easy to show that the inequality is re-established with larger $s$. Hence, $\underline{d}$ can be further increased while respecting the inequality.

Moreover, given that $U_{s}^{d}\left(\theta_{s}^{d}(\tau), \tau\right)-U^{0}\left(\theta^{0}(\tau), \tau\right)$ is monotonic decreasing in $\tau$ for $\tau \in\left(\tau_{s}^{B}, \tau^{A}\right)$, there may be cases where the preferred regulation curve is $\theta_{s}^{d}(\tau)$ below some threshold value of $\tilde{\tau} \in\left(\tau_{s}^{B}, \tau^{A}\right)$ and $\theta^{0}(\tau)$ above that value. In other words, though private mitigation, with its associated lower regulation level, may be preferred at low tariff rates (that is, with a high degree of trade openness), it may not the case at higher rates, as the relative benefits from private mitigation are reduced. A similar argument holds for the preferred tariff curve since $U_{s}^{d}\left(\theta, \tau_{s}^{d}(\theta)\right)-U_{s}^{0}\left(\theta, \tau^{0}(\theta)\right)$ is decreasing in $\theta$ for $\theta \in\left(\theta_{s}^{B}, \theta^{A}\right)$. This possibility is illustrated in figure 3 .

\section{Endogenous policy: Political regimes compared}

The preceding analysis provides the background for the comparative analysis of political regimes concerning the choices of environmental regulation and of trade openness that emerge in a political equilibrium. In conducting this analysis, we will see that the technology of private mitigation plays an important but different role in each type of regime.

To proceed further, we first need to specify more precisely what is meant by mitigation technology, and then by the nature of political regimes. In what follows, points A to D referred to are illustrated in figure 2 as well as in figure 3. 


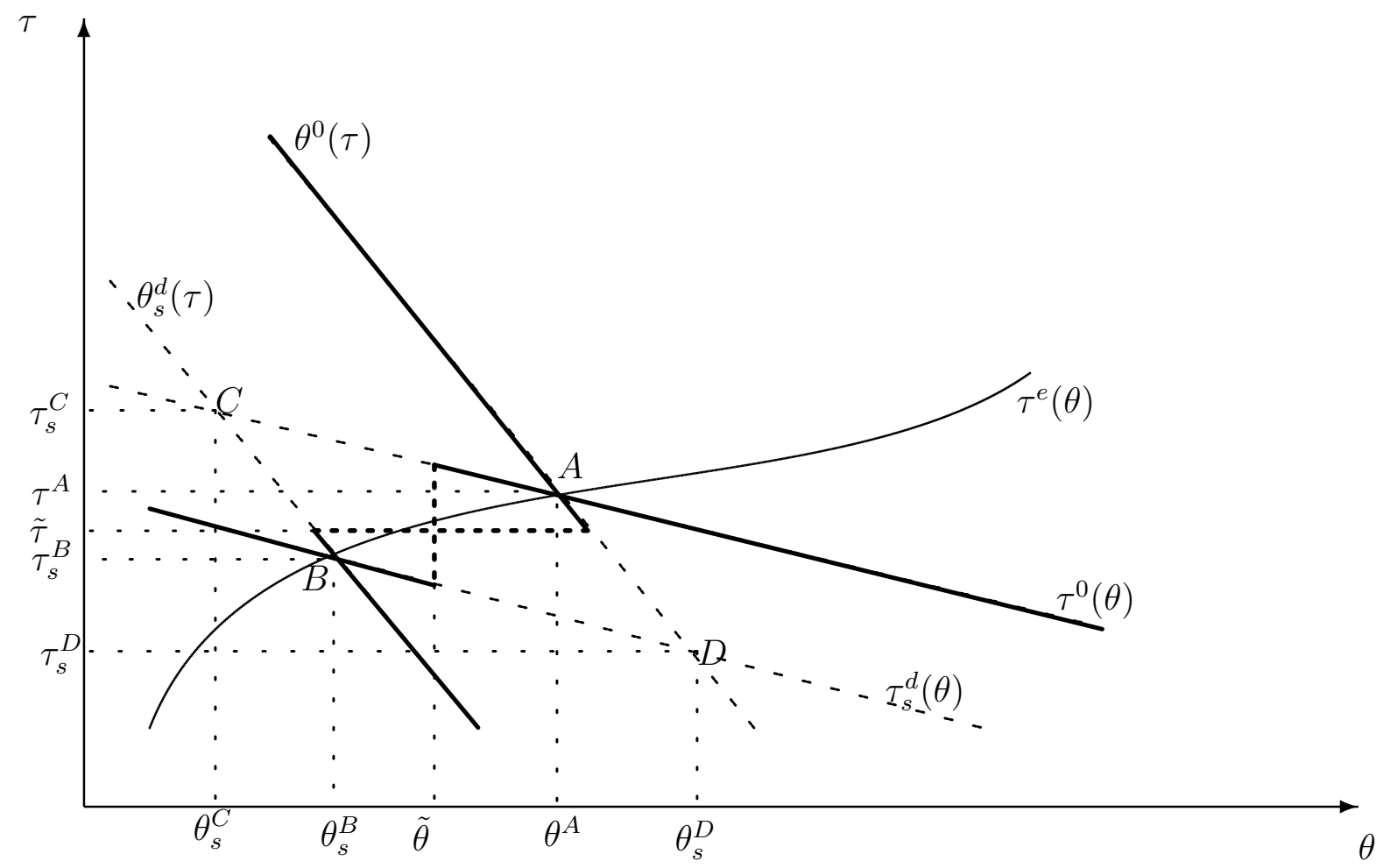

Figure 3: The decision to reduce private mitigation with higher regulation or tariffs

\subsection{A menu of mitigation technologies}

To study the role of mitigation technology, we shall consider four types of private mitigation technologies ranked according to their cost as follows: $\underline{d}_{1}<$ $\underline{d}_{2}<\underline{d}_{3}<\underline{d}_{4}$. For each cost $\underline{d}_{i}, i \in\{1,2,3,4\}$, there will therefore correspond a different individually preferred policy combination which is decreasing in $i$ and increasing in $s$ (see proposition 7 ). In order to keep track of this, type $s$ 's preferred policy combination when the mitigation cost is $\underline{d}_{i}$ will be referred to as $\left(\theta_{i s}^{B}, \tau_{i s}^{B}\right)$.

We assume the different costs of private mitigation to be such that they yield one or the other of the following outcomes concerning the level of private mitigation adopted by richer and poorer individuals: 
Prohibitive cost $\underline{d}_{4}$ : Private mitigation is not a practical option even at point $B$ in figures 2 or 3 for both rich and for poorer citizens. That is, $U_{\bar{s}}^{0}\left(\theta^{A}, \tau^{A}\right)>U_{\bar{s}}^{d}\left(\theta_{4}^{B}, \tau_{4}^{B}\right){ }^{15}$

High cost $\underline{d}_{3}$ : The cost is such that option $B$ is preferred to $A$ by type $\bar{s}$, but not $\underline{s}$. However, above some given intermediate values of $\tilde{\theta} \in$ $\left(\theta_{3 \bar{s}}^{B}, \theta^{A}\right)$ and $\tilde{\tau} \in\left(\tau_{3 \bar{s}}^{B}, \tau^{A}\right)$, the welfare of $\bar{s}$ is higher without private mitigation. Formally, we have $U_{\bar{s}}^{d}\left(\theta_{\bar{s}}^{B}, \tau_{3 \bar{s}}^{B}\right)>U_{\bar{s}}^{0}\left(\theta^{A}, \tau^{A}\right), U_{\bar{s}}^{d}\left(\tilde{\theta}, \tau_{\bar{s}}^{d}(\tilde{\theta})\right)=$ $U_{\bar{s}}^{0}\left(\tilde{\theta}, \tau^{0}(\tilde{\theta})\right)$ and $U_{\bar{s}}^{d}\left(\theta_{\bar{s}}^{d}(\tilde{\tau}), \tilde{\tau}\right)=U_{\bar{s}}^{0}\left(\theta^{0}(\tilde{\tau}), \tilde{\tau}\right)$. Consequently, type $\bar{s}$ ' preferred tariff curve is $\tau^{d}(\theta)$ for $\theta<\tilde{\theta}$ and $\tau^{0}(\theta)$ for $\theta>\tilde{\theta}$, and analogously for the preferred regulation curve. (See figure 3.)

Moderate cost $\underline{d}_{2}$ : In this case, the cost is such that type $\bar{s}$ chooses to spend on private mitigation at options $A, C$ and $D$ in figure 3 , but type $\underline{s}$ never does. This implies that $U_{\bar{s}}^{d}\left(\theta^{A}, \tau^{A}\right)>U_{\bar{s}}^{0}\left(\theta^{A}, \tau^{A}\right)$, that the preferred tariff curve is $\tau_{\bar{s}}^{d}(\theta)$ for $\theta \leq \theta_{\bar{s}}^{D}$, and the preferred regulation curve is $\theta_{\bar{s}}^{d}(\tau)$ for $\tau \leq \tau_{\bar{s}}^{C}$.

Low cost $\underline{d}_{1}$ : Both types prefer to spend on private mitigation in a dirtier environment; that is, $U_{\underline{s}}^{0}\left(\theta^{A}, \tau^{A}\right)<U_{\underline{s}}^{d}\left(\theta_{1 \underline{s}}^{B}, \tau_{1 \underline{s}}^{B}\right)$.

Note that except for the low cost case $\underline{d}_{1}$, we assume that for individual $\underline{s}$, private mitigation is never chosen. Besides a change in its cost $\underline{d}$, we assume no other change in the properties of the private mitigation function defined in $(7)$.

\subsection{Alternative political regimes}

We now turn to detailed specification of the three types of political regimes and their associated equilibria. The analysis proceeds by specifying a set of related but distinct optimization problems that can be conveniently used to derive the associated policies and pollution level for each regime type. In this section, policies are described for each regime considered by itself. A comparative analysis follows later. Again points A to D in figures 2 and 3 are used to illustrate our arguments.

The analysis is simplified by restricting attention to two income groups, rich and poor, introduced and analyzed to some extent earlier. This proves adequate for our purposes, and does not greatly restrict the ability to consider

\footnotetext{
${ }^{15}$ Radioactive leakage from a nuclear reactor may fit into this category.
} 
the consequences of increased inequality in a later section. Since there are two policies, the median voter model does not apply in the fully democratic case, where a more general spatial voting approach to analysis of equilibrium is used. ${ }^{16}$ In the non-democratic regimes, the rich are treated as a dominant elite, and the poor as ordinary citizens who may or may not vote on some dimension of public policy.

\subsubsection{The autocratic regime}

We label as autocratic (AU), a political regime in which a rich elite chooses both environmental regulation and trade openness unilaterally. Here the ordinary (poorer) citizen has no voice whatsoever, and government policies in the service of the elite can be described by maximizing the welfare of the high-income elite:

$$
\max _{\theta, \tau} S^{A U}=U_{\bar{s}}^{*}(\theta, \tau) .
$$

For each private mitigation cost, the resulting political equilibrium choice of policies is reported in table 1.

\begin{tabular}{cc} 
Mitigation cost & Policy equilibrium \\
\hline$\underline{d}_{1}$ & $\left(\theta_{1 \bar{s}}^{B}, \tau_{1 \bar{s}}^{B}\right)$ \\
$\underline{d}_{2}$ & $\left(\theta_{2 \bar{B}}^{B}, \tau_{2 \bar{s}}^{B}\right)$ \\
$\underline{d}_{3}$ & $\left(\theta_{3 \bar{s}}^{B}, \tau_{3 \bar{s}}^{B}\right)$ \\
$\underline{d}_{4}$ & $\left(\theta^{A}, \tau^{A}\right)$ \\
\hline
\end{tabular}

Table 1: Mitigation costs and environmental policy in an autocratic regime

In the autocratic regime, the government always chooses policy combinations at the intersection of the high-income group's preferred regulation and tariff curves. Hence, the policy choices fall on efficiency curve $\tau^{e}(\theta)$. In terms of pollution level, if we let $Q_{i}^{r}$ denote the equilibrium pollution level under political regime $r \in\{A U, S D, W D 1, W D 2\}$ and mitigation cost $\underline{d}_{i}$, we have $Q_{3}^{A U}>Q_{2}^{A U}>Q_{1}^{A U}>Q_{4}^{A U}$. The pollution level is highest in the case where

\footnotetext{
${ }^{16} \mathrm{~A}$ similar simplification is used in other political economy analyses, such as that of Acemoglu and Robinson (2006). In the spatial voting equilibrium, outcomes reflect a balancing of heterogeneous interests in the electorate, and the character of that equilibrium can be investigated well enough in the present context with just two groups.
} 
the private mitigation cost is low enough to still be adopted by the rich, but so high that they become reticent to sacrifice additional consumption income through public policies. The pollution level is lowest when private mitigation is too costly to be adopted by anyone. There is thus a discontinuity in the relationship between the cost of private mitigation and the resulting pollution level: pollution initially increases with $\underline{d}$ and then drops once the cost of mitigation rises above a threshold value.

As far as ordinary (poorer) citizens are concerned, the autocratic regime leads to equilibria in which there is too much pollution in intermediate cases $\underline{d}_{2}$ and $\underline{d}_{3}$, just the right amount at high cost $\underline{d}_{4}$, and too little pollution at low cost $\underline{d}_{1}$. The latter case is driven by the fact that once they adopt private mitigation, citizens become more reticent than the elite to sacrifice more of their consumption in order to reduce pollution.

It may be noted that the above menu of possibilities illustrates that, except in the low mitigation cost case, a traditional normal-good based prediction about environmental quality will not provide an adequate explanation of individual demands for regulation. This is also so for the other regimes considered below.

\subsubsection{Strong Democracy}

We define a strong democratic regime (SD) to be one in which a political equilibrium can be represented by maximizing a weighted sum of utilities of all citizens in the country:

$$
\max _{\theta, \tau} S^{S D}=\gamma U_{\bar{s}}^{*}(\theta, \tau)+(1-\gamma) U_{\underline{s}}^{*}(\theta, \tau),
$$

where $\gamma$ denotes the relative influence weight of the high-income-share group in the political equilibrium. This model of a fully democratic state makes use of the well-known Representation Theorem that shows how spatial voting equilibria can be calculated using a synthetic optimization problem like (28) - see for example, Couglin (1992) and Hettich and Winer (1999). Note that the objective in (28) is not a social welfare function. The particular weights in it, as well as its functional form, are determined by the nature of the Nash political equilibrium. They are not chosen as part of a social plan.

The intuition behind the theorem is that when voting behavior depends only on how citizens think that parties attend to their individual well-being, strong political competition forces each party to move towards the Pareto 
frontier or risk losing votes to an opposition that can promise more welfare for politically sensitive groups of voters (with relatively high $\gamma$ ) without reducing the welfare of others.

In the present environmental context, equilibrium in a strong democracy always involves a policy combination located along the pollution efficiency curve $\tau^{e}(\theta)$. Hence, the political equilibrium of the fully democratic government is characterized by

$$
\begin{aligned}
& \gamma\left\{u_{c}\left(c_{\bar{s}}^{*}\right) \bar{s}\left[z_{\theta}+z_{\tau} \tau^{e \prime}(\theta)\right]+h_{Q}\left(d_{\bar{s}}^{*}, Q\right)\left[Q_{\theta}+Q_{\tau} \tau^{e \prime}(\theta)\right]\right\}= \\
& \quad(1-\gamma)\left\{u_{c}\left(c_{\underline{s}}^{*}\right) \underline{s}\left[z_{\theta}+z_{\tau} \tau^{e \prime}(\theta)\right]+h_{Q}\left(d_{\underline{s}}^{*}, Q\right)\left[Q_{\theta}+Q_{\tau} \tau^{e \prime}(\theta)\right]\right\} .
\end{aligned}
$$

The terms between square brackets denote general equilibrium effects in terms of national income and pollution changes, and are multiplied by the respective individual sensitivities $u_{c} s$ and $h_{Q}$. This means, for instance, that even in a situation where the poor wield little direct political clout - that is $(1-\gamma)$ is small - they may still have a significant impact on the equilibrium policy of a democratic government if their individual sensitivities to pollution are much higher than those of the higher income individuals, because this affects their voting behavior.

The resulting political equilibrium choice of policies are reported in table 2 .

\begin{tabular}{cc} 
Mitigation cost & Policy equilibrium $\theta(\gamma)$ \\
\hline$\underline{d}_{1}$ & on $\tau^{e}(\theta)$ with $\theta(\gamma) \in\left(\theta_{1 s}^{B}, \theta_{1 \bar{s}}^{B}\right)$ and $\theta^{\prime}(\gamma)>0$ \\
$\underline{d}_{2}$ & on $\tau^{e}(\theta)$ with $\theta(\gamma) \in\left(\theta_{2 \bar{s}}^{B}, \theta^{A}\right)$ and $\theta^{\prime}(\gamma)<0$ \\
$\underline{d}_{3}$ & on $\tau^{e}(\theta)$ with $\theta(\gamma) \in\left(\theta_{3 \bar{s}}^{B}, \theta^{A}\right)$ and $\theta^{\prime}(\gamma)<0$ \\
$\underline{d}_{4}$ & $\left(\theta^{A}, \tau^{A}\right)$ \\
\hline
\end{tabular}

Table 2: Mitigation costs and environmental policy in a strong democratic regime

At prohibitive cost $\underline{d}_{4}$, the equilibrium policy coincides with both group's preferred policy combination and the pollution level is lowest.

At intermediate cost levels $\underline{d}_{2}$ and $\underline{d}_{3}$, the policy outcome is located between points $B_{\bar{s}}$ and $A$ somewhere along the efficiency curve and moves up from $B_{\bar{s}}$ towards $A$ as the influence of the poor $(1-\gamma)$ increases. The movement is continuous in the case of $\underline{d}_{2}$. With $\underline{d}_{3}$, however, there is a discontinuity in policy equilibrium $\theta(\gamma)$. Indeed, the democratic government 
chooses a policy along curve $\tau^{e}(\theta)$ that increases continuously from $\theta_{\bar{s}}^{B}$ to $\tilde{\theta}$ as $\gamma$ initially decreases from 1 . But for all influence values below the one that yields equilibrium policy $\tilde{\theta}$, the policy outcome is $\left(\theta^{A}, \tau^{A}\right)$.

At lost cost $\underline{d}_{1}$, equilibrium policies now fall between points $B_{\underline{s}}$ and $B_{\bar{s}}$ and moves down from $B_{\bar{s}}$ towards $B_{\underline{s}}$ as the influence of the poor increases.

As far as the pollution level is concerned, we obtain that under democracy, the pollution level is lowest when the cost of private mitigation is prohibitively high, just as in the case of an autocratic regime; it increases with the influence of the rich at intermediate mitigation cost levels; while it increases with the influence of the poor at low mitigation cost levels.

\subsubsection{The weak democracy}

The strong or fully democratic regime defined above assumes that all citizens vote in a manner that takes into account both policy dimensions, and political platforms are shaped accordingly. But this will not be so in all democratic contexts. Rodrik (1992), for instance, investigates situations of what he calls subordinate government in which a rich elite leads by setting some policies, with a democratically elected (but subordinate) government acting as a follower in setting other policies. Besley and Burgess (2002) argue that influence is linked to the availability of information about policies, and that politicians may exploit the fact that the poor are often not well informed about some of their actions. Damania, Fredriksson and List (2004) propose a model in which there is an interaction between the choice of trade tariff and environmental taxation which is dependent on the corruption level. Because of corruption, producers gain influence over environmental policies. ${ }^{17}$ List and Sturm (2006) classify policy issues as either "frontline" or "secondary" and develop models where the voter's effective influence varies across issues.

Although the justifications may vary, a fundamental consequence of these and many other analogous situations is that some citizens may control aspects of public policy in nominally democratic regimes to a greater extent than others. This situation has important implications in the environmental

\footnotetext{
${ }^{17}$ This story is reminiscent of arguments heard in Costa Rica by one author during the summer of 2007 leading up to an October referendum on a free trade agreement with Central America and the USA. Many believed that due to corrupt civil servants and politicians, Costa Rica would not be able to retain high environmental and labor standards once opened to trade, unlike Canada with NAFTA. Hence, though they could influence trade policy through a referendum, many felt that they would lose influence over social policies.
} 


\begin{tabular}{ccc} 
Mitigation cost & \multicolumn{2}{c}{ Policy equilibrium } \\
& case 1 & case 2 \\
\hline$\underline{d}_{2}$ & $\left(\theta^{C}, \tau^{C}\right)$ & $\left(\theta^{D}, \tau^{D}\right)$ \\
$\underline{d}_{3}$ & $\left(\theta^{A}, \tau^{A}\right)$ & $\left(\theta^{A}, \tau^{A}\right)$ \\
$\underline{d}_{4}$ & $\left(\theta^{A}, \tau^{A}\right)$ & $\left(\theta^{A}, \tau^{A}\right)$ \\
\hline
\end{tabular}

Table 3: Mitigation costs and environmental policy in a weak democracy

context. To see why, we may consider the following two polar cases: (1) The high-income group, or elite, sets the degree of environmental regulation stringency, while the government, responding to the mass of (lower income) voters, chooses the degree of trade openness; (2) The high-income elite sets the tariff, and lower income voters as a group effectively choose the degree of environmental regulation.

In either case, the outcome is modeled as a Nash equilibrium choice of policy. In case 1, the equilibrium policies fall at the intersection between the elite's preferred environmental regulation curve and the low income voters' preferred tariff curve. In case 2 , the equilibrium policy outcome falls at the intersection between the high income group's preferred trade tariff curve and the low income group's preferred environmental regulation curve.

Table 3 reports the political equilibria corresponding to each mitigation cost level. (Low cost $\underline{d}_{1}$ is omitted for brevity.)

As in the autocracy and democracy cases, with high mitigation cost $\underline{d}_{4}$, we still find political equilibria at the most stringent policies $\left(\theta^{A}, \tau^{A}\right)$. Both groups' preferred policy combinations are perfectly aligned and pollution is lowest.

With $\underline{d}_{3}$, the equilibrium is also at $\left(\theta^{A}, \tau^{A}\right)$. One can indeed verify that for each case, the respectively preferred regulation and tariff curves cross at point $A$ only. In the Nash setting, the reason is as follows: If the rich set a low regulation level while buying private mitigation, the poor, who cannot afford to mitigate, react by voting for a government that adopts a high tariff rate. But at the high tariff rate, the rich prefer to forgo private mitigation and replace it with increased regulation. The poor then react by 'choosing' a somewhat lower tariff rate. And so on. With the help of figure 3, one can verify that there is a convergence towards point $A$, which constitutes a stable and unique equilibrium for both heterogeneous influence cases 1 and 2 .

When the cost of mitigation drops to $\underline{d}_{2}$, however, the rich always choose 
to mitigate. As a result, in case 1, they set a low regulation level, to which the government responding to ordinary (poorer) citizens reacts by choosing a high tariff rate at equilibrium point $C$. In case 2 , the relevant policy curve for the high-income group is $\tau_{\bar{s}}^{d}(\theta)$ while that of the low-income group is $\theta^{0}(\tau)$. The policy outcome is at point $D$ with a high regulation level and a low tariff rate. $^{18}$

\subsection{A comparative analysis}

We first observe that when private mitigation is prohibitively costly, equilibrium public policy choices are not affected by the nature of the regime. The interests of both income groups coincide in the absence of private mitigation. ${ }^{19}$ Everyone wants to rely entirely on public policy to reduce pollution. The resulting pollution level is the lowest in all regimes types, and the pollution burden is distributed equally across individuals because no one privately mitigates.

At the other end of the private mitigation cost spectrum, when mitigation costs are low so that both rich and poor prefer to adopt private mitigation and reduce the level of public regulation, regime type matters. Just as in the standard normal good case, the rich want stricter public policies than the poor. An autocratic regime may thus adopt more stringent policies than will a democratic one in which the poor pressure the government for less regulation and hence more income. We thus obtain that an autocratic government is more eco-friendly than a democratic one and the pollution burden is equally distributed.

At intermediate private mitigation cost levels, the rich prefer to privately mitigate and advocate lax public policies while the poor prefer not to privately mitigate, and to push for more stringent public policy. Contrary to the low-cost case, environmental quality is not a normal good anymore. Autocracy therefore leads to a highly polluted environment, with the poor being entirely exposed. The strong democracy adopts generally more stringent public policies, with pollution levels declining as the influence of the poor increases.

\footnotetext{
${ }^{18}$ This result is consistent with the empirical work of Damania, Fredriksson and List (2003), who find that in more corrupt countries, trade openness is positively linked to stringency of regulation regarding lead in gasoline.

${ }^{19}$ Recall that though the rich pay more for public policies, they also have a lower marginal utility of income. We assumed that both effects cancel out as income share increases.
} 
In these intermediate cases, strong democracy is more eco-friendly than autocracy. The pollution burden is unequally distributed for both regime types, but the poor suffer more from pollution under an autocratic government.

In weak democracies, a relatively high intermediate mitigation cost level $\underline{d_{3}}$ (when mitigation is expensive for the rich but still feasible) leads to an equilibrium with stringent public policies and low pollution while in autocracy this leads to the opposite. In terms of the pollution level, the strong democratic case falls in-between the autocracy and the weak democracy cases. This result is due to the fact that in weak democracies, if the rich try to lower the level of public intervention in one dimension and privately mitigate, the poor will compensate with a high level in the other, since they cannot privately mitigate. This, in turn, makes private mitigation less attractive to the rich. In anticipation, since mitigation is relatively costly, the rich also turn to public policies without private mitigation.

Things are different with relatively low intermediate mitigation costs. In such cases, we cannot compare directly the level of pollution between a weak democracy and either strong democracy or autocracy. If the rich control the regulation level in a weak democracy, for instance, they will set it low and buy private mitigation. Being fully exposed to pollution, poorer citizens pressure the government to react with a high tariff rate. Since the two public policy instruments move in opposite directions, we cannot say whether the resulting pollution level is lower or higher than in the other, purer regimes.

As a whole, these comparisons establish clearly that the cost of private mitigation is a critical determinate of differences in policy equilibria across regime types. Differences across regimes in environmental policies and pollution levels are most evident for types of pollution that can be addressed partially or fully via private mitigation.

\subsection{The Effect of Increased Income Inequality}

The foregoing analysis allows us to make predictions about how democracy affects changes in environmental stringency when income inequality increases. For brevity, we shall compare the cases of autocracy and strong democracy only.

We define an increase in inequality as a strictly higher income share for the rich $\left(\Delta^{+} \bar{s}\right)$ and a strictly lower income share for the poor $\left(\Delta^{-} \underline{s}\right)$. Population sizes and relative political influence influence weights are, as before, assumed constant. Depending on the initial values of $\underline{d}, \bar{s}$ and $\underline{s}$, we may distinguish 
two possible scenarios.

Scenario 1: Suppose that initially, when income inequality is relatively low, both income groups prefer overall policy combination $\left(\theta^{A}, \tau^{A}\right)$ in figure 2. This means that both groups have the same interests in public policy because they both prefer stringent environmental policies while saving on private mitigation costs. Autocratic and democratic regimes will thus yield the same policy outcomes.

Given proposition 1, an increase in $\bar{s}$ will eventually lead the rich to switch to private mitigation. The rich then prefer less stringent public policies at $\left(\theta_{\bar{s}}^{B}, \tau_{\bar{s}}^{B}\right)$. Whether the political regime is of the autocratic or strong democratic type, increased inequality therefore leads to laxer environmental policies. However, since the poor still exert some influence in a democratic regime, the extent of the reduction in government action (due to increased inequality) is less marked under democracy.

But the story does not end there. According to proposition 7, once the rich can afford private mitigation, further increases in $\bar{s}$ cause them to prefer more stringent environmental policies. Regardless of the political regime, we then have the opposite result that increased inequality beyond this point leads to a cleaner environment.

Scenario 2: Suppose that initially, and in contrast to the first scenario, when income inequality is relatively low, individuals in both groups prefer to privately mitigate. In accordance with proposition 7 , the rich then prefer more stringent regulation than the poor.

Further increases in inequality lead the poor to demand less stringent environmental policies as long as they still choose to privately mitigate. The rich, on the other hand, want more stringent environmental policies. In an autocratic regime, this leads to more stringent policy. In a strong democracy, in contrast, the outcome is indeterminate as each group pulls different policies in opposite directions.

But according to proposition 7, further increases in inequality will eventually lead the poor to prefer stricter environmental policies while forgoing private mitigation. When that takes place, their preference jumps from being less stringent to being more stringent than that of the elite. This makes little difference under an autocratic regime as the rich still choose to privately mitigate. But in a fully democratic one, increased inequality then unambiguously 
leads to the adoption of more stringent environmental policies.

In general, we see that the effects on the nature of environmental regulation of increased inequality depend on initial conditions, and are nonlinear in the extent of the change in the distribution of incomes. This analysis indicates that empirical work on the relationship of inequality and environmental policy will be complex, and it is easy to see why imperfect controls in a regression equation may lead to a wide variety of results.

\section{Conclusion}

In this paper we have explored the roles of private mitigation and income inequality in the political economy of the environment. While richer citizens may prefer the use of a private defence against pollution and the higher income that comes from specialization and trade in dirty goods, poorer citizens may prefer collective intervention in order to reduce their exposure. Income inequality, whatever its source, causes divergence of interests because of the feasibility of private mitigation as an alternative to collective action. This divergence of interests is exacerbated by trade, since specialization in dirty production generates pollution as well as higher incomes.

Equilibria in three types of regimes are compared: autocratic, weak and strong democracies. In autocracy, only a rich elite decides on the course of government policy. In contrast, in strong democracies all citizens exercise voice in the setting of both policy instruments - the degree of regulation of emissions, and the degree of trade openness (via an import tariff) which affects the degree of specialization of the economy in dirty production. In the weak democracy, the elite is decisive on one dimension of most interest to it, while a weak government responds as best it can to citizen demands concerning the remaining policy issue.

The equilibria in these regimes are modeled using a sequence of appropriate, related optimization problems, and are distinguished by the influence exercised by ordinary (poorer) citizens in each of the two key policy dimensions. The multi-dimensional nature of the issue space allows for the possibility of variation in the influence of each group with each policy dimension, a realistic feature of our model that sometimes leads to difficulties in comparing the eco-friendliness of different regimes.

We show that the divergence of interests is most acute and the difference across regimes most marked when existing technology (or the type of pollution) provides for intermediate or low levels of the cost of private mitigation. 
When the cost of mitigation is very high, divergence of interests in the population is reduced and political outcomes across regimes tends to converge. When the cost of privately mitigating is very high, both rich elites and ordinary citizens prefer collective action to deal with pollution, and the health consequences pollution will be equally distributed across the population even in an autocracy.

In the intermediate cost cases, when the rich, or the elite, can afford to mitigate the consequences of pollution more than ordinary citizens, policy outcomes diverge substantially with the type of regime. It is possible that the elite in non-democratic regimes will adopt both tight environmental regulations along with a high level of trade openness, a political outcome that lies outside of the fully democratic arena, and that may possibly be qualified as environmentally friendly.

We also compare regimes with respect to the level of pollution generated. Although democracy is less generally polluting than autocracy, because poorer citizens exercise influence in a strong democracy and cannot afford to mitigate privately to the same extent, our analysis indicates that when the rich exert heavy influence in a fully democratic state, weak democracies may do better.

We conclude by restating the central theme of the paper: acknowledging the possibility of privately mitigating the health consequences of pollution at a cost has important consequences for the study of the political economy of the environment.

\section{References}

Acemoglu, Daron, and James S. Robinson (2006) Economic Origins of Dictatorship and Democracy (Cambridge University Press)

Anderson, James E., and J. Peter Neary (2005) Measurig the Restrictiveness of International trade Policy (Cambridge, Mass.: The MIT Press)

Ash, M., and T.R. Fetter (2004) 'Who lives on the wrong side of the environmental tracks? Evidence from the EPA's risk-screening environmental indicator model.' Social Science Quarterly 85, 441-462

Bartik, Timothy J. (1988) 'Evaluating the benefits of non-marginal reductions in pollution using information on defensive expenditures.' Journal of Environmental Economics and Management 15, 111-27 
Bernard, Philippe (2006) 'La rage d'Espérance Edoukou, victime des déchets toxiques déversés à Abidjan.' Le Monde 13.09.06

Besley, Timothy, and Robin Burgess (2002) 'The political economy of government responsiveness: Theory and evidence from india.' The Quarterly Journal of Economics pp. 1415-51

Bradsher, Keith, and David Barbosa (2006) 'Pollution from chinese coal casts a global shadow.' The New York Times 11.06.06

Brooks, Nancy, and Rajiv Sethi (1997) 'The distribution of pollution: Community characteristics and exposure to air toxics.' Journal of Environmental Economics and Management 32, 233-250

Brunekreef, B., and S.T. Holgate (2002) 'Air pollution and health.' The Lancet 360, 1233-42

Chichilnisky, Graciela (1994) 'North-south trade and the global environment.' The American Economic Review 84(4), 851-874

Coase, R. H. (1960) 'The problem of social cost.' The Journal of Law and Economics III, 1-44

Congleton, Roger D. (1992) 'Political institutions and pollution control.' The Review of Economics and Statistics 74, 412-421

Copeland, B.R., and M.S. Taylor (1994) 'North-south trade and the environment.' Quarterly Journal of Economics 109, 755-87

(2003) Trade and the Environment: Theory and Evidence (Princeton, USA and Oxford, UK: Princeton University Press)

Corden, W. M. (1984) 'The normative theory of international trade.' In Handbook of International Economics, ed. R. W. Jones and P. B. Kenen, vol. I (Elsevier Science) chapter 2, pp. 63-130

Coughlin, Peter J. (1992) Probabilistic Voting Theory (Cambridge University Press)

Courant, Paul N., and Richard C. Porter (1981) 'Averting expenditure and the cost of pollution.' Journal of Environmental Economics and Management 8, 321-29 
Damania, Richard, Per G. Fredriksson, and John A. List (2003) 'Trade liberalization, corruption and environmental policy formation: Theory and evidence.' Journal of Environmental Economics and Management $46,490-512$

(2004) 'The multiplier effect of globalisation.' Economics Letters $83,285-292$

Dasgupta, S., K. Hamilton, K. Pandey, and D. Wheeler (2006) 'Environment during growth: Accounting for governance and vulnerability.' World Development 34, 1597-1611

Eriksson, Clas, and Joakim Persson (2003) 'Economic growth, inequality, democratization, and the environment.' Environmental and Resource Economics 25, 1-16

Evans, Mary F., and V. Kerry Smith (2005) 'Do new health conditions support mortality-air pollution effects?' Journal of Environmental Economics and Management 50, 496-518

Farzin, Y.Hossein, and Craig A. Bond (2006) 'Democracy and environmental quality.' Journal of Development Economics 81, 213-235. Paper presented at the 2005 Canadian Resource and Environmental Economics Annual Meeting, HEC Montreal

Fredriksson, Per G., and Jim R. Wollscheid (2007) 'Democratic institutions versus autocratic regimes: The case of environmental policy.' Public Choice 130, 381-393

Fredriksson, Per G., Eric Neumayer, Richard Damania, and Scott Gates (2005) 'Environmentalism, democracy, and pollution conrol.' Journal of Environmental Economics and Management 49, 343-365

French, Howard W. (2005) 'Riots in Shanghai suburb as pollution protest heats up.' The New York Times 19.07.05

Hanna, Brid Gleeson (2007) 'House values, incomes, and industrial pollution.' Journal of Environmental Economics and Management 54, 100-112

Hettich, Walter, and Stanley L. Winer (1999) Democratic Choice and Taxation: A Theoretical and Empirical Analysis (New York: Cambridge University Press) 
Heyes, Anthony, and Sandeep Kapur (2010) 'Regulatory attitudes and environmental innovation: A strategic model combining internal and external r\&d'

Hillman, Arye L., and Heinrich W. Ursprung (1992) 'The influence of environmental concerns on the political determination of trade policy.' In The Greening of World Trade Issues, ed. Kym Anderson and Richard Blackhurst (Harvester Wheatsheaf) chapter 10

Hotte, Louis, and Stanley L. Winer (2008) 'The demands for environmental regulation and for trade in the presence of private mitigation.' WP2509, CESIFO

Hueth, Brent, and Tigran Melkonyan (2009) 'Standards and the regulation of environmental risk.' Journal of Regulatory Economics 36, 219-246

Jayachandran, Seema (2008) 'Air quality and early-life mortality: Evidence from Indonesia's wildfires.' NBER Working Papers 14011, National Bureau of Economic Research, Inc, May

Jones, R. W. (1969) 'Tariffs and trade in general equilibrium: Comment.' American Economic Review 59, 418-24

Kahn, Matthew E., and John G. Matsusaka (1997) 'Demand for environmental goods: Evidence from voting patterns on California inititives.' Journal of Law and Economics XL, 137-173

Kristrom, Bengt, and Pere Riera (1996) 'Is the income elasticity of environmental improvements less than one?' Environmental and Resource Economics 7(1), 45-55

List, John A., and Daniel M. Sturm (2006) 'How elections matter: Theory and evidence from environmental policy.' The Quarterly Journal of Economics 121, 1249-81

Markusen, James R. (2010) 'Putting per-capita income back into trade theory.' Discussion Paper 7790, CEPR

Mayer, Wolfgang (1984) 'Endogenous tariff formation.' The American Economic Review 74(5), 970-985 
McAusland, Carol (2003) 'Voting for pollution policy: The importance of income inequality and openness to trade.' Journal of International Economics 61, 425-451

McKitrick, Ross, and Robert A. Collinge (2002) 'The existence and uniqueness of optimal pollution policy in the presence of victim defense measures.' Journal of Environmental Economics and Management 44, 106122

Mining in Peru: Halting the rush against gold (2005) The Economist

Mitra, Devashish, and Vitor Trindade (2005) 'Inequality and trade.' Canadian Journal of Economics 38, 1253-71

Murdoch, James C., Todd Sandler, and Keith Sargent (1997) 'Tale of two collectives: Sulphur versus nitrogen oxids emision reduction in europe.' Economica 64, 281-301

Neidell, Matthew (2009) 'Information, avoidance behavior, and health.' Journal of Human Resources 44, 450-478

Neidell, Matthew J. (2004) 'Air pollution, health, and socio-economic status: The effect of outdoor air quality on childhood asthma.' Journal of Health Economics 23, 1209-1236

O'neill, Marie S., and Al. (2003) 'Health, wealth, and air pollution: Advancing theory and methods.' Environmental Health Perspectives 111, 18611870

Pearce, J., S. Kingham, and P. Zawar-Reza (2006) 'Every breath you take? environmental justice and air pollution in Christchurch, new zealand.' Environment and Planning A 38, 919-938

Pethig, R. (1976) 'Pollution, welfare, and environmental policy in the theory of comparative advantage.' Journal of Environmental Economics and Management 2, 160-169

Rodrik, Dani (1992) 'Political economy and development policy.' European Economic Review pp. 329-336 
Rosado, Marcia A. et Al. (2006) 'Combining averting behavior and contingent valuation data: An application to drinking water treatment in Brazil.' Environment and Development Economics 11, 729-746

Schulze, Günter G., and Heinrich W. Ursprung (2001) 'The political economy of international trade and the environment.' In International Environment Economics: A Survey of the Issues, ed. Günter G. Schulze and Heinrich W. Ursprung (Oxford: Oxford University Press) chapter 4, pp. $62-83$

Shibata, Hirofumi, and J. Steven Winrich (1983) 'Control of pollution when the offended defend themselves.' Economica 50, 425-437

Torras, Mariano, and James K. Boyce (1998) 'Income, inequality, and pollution: A reassessment of the environmental Kuznets curve.' Ecological Economics 25, 147-160 